\title{
A Curatorial Model for Teaching Renaissance Book History in Canada
}

\author{
JANELLE JENSTAD AND ERIN E. KELLY
}

University of Victoria

\begin{abstract}
Only by holding early printed books can students learn both the strangeness of the past and its oddly familiar struggle with technological innovation. Even partial collections like the one at the University of Victoria have enough rare books to serve these purposes. But how do we teach book culture and intellectual history when we do not have multiple or even representative books from many authors, countries, and sometimes whole decades? We adopt a curatorial teaching model that invites students to find, select, and chart a narrative through the materials that we do have. This article describes our curatorial projects in the hope that others will undertake similar endeavours. It also explains how the very partiality of our collection has generated wonderful opportunities for students to learn not just book history but also the history of Canadian universities, libraries, collectors, and Renaissance studies.
\end{abstract}

C'est seulement en ayant des livres anciens entre les mains que les étudiants peuvent faire l'expérience de l'altérité du passé et de la familiarité des difficultés liées aux innovations technologiques. Même une collection limitée comme celle de la University of Victoria est suffisante pour atteindre ces objectifs. Mais comment peut-on enseigner l'histoire et la culture du livre et l'histoire intellectuelle lorsque nos ressources ne contiennent pas suffisamment de livres ou des livres représentatifs de plusieurs auteurs, pays, voire de décennies? Nous avons adopté un modèle d’enseignement de la conservation invitant les étudiants à trouver, sélectionner, et élaborer un récit historique à travers les ressources auxquelles nous avons accès. Cet article décrit nos projets de conservation dans l'espoir de susciter d'autres projets similaires. Nous y expliquons aussi comment une collection même très partielle comme la nôtre a donné le jour à d'extraordinaires possibilités d'apprentissage pour les étudiants, non seulement dans le domaine de l'histoire du livre mais aussi en histoire des universités, des bibliothèques, et des collectionneurs canadiens, dans le domaine des études de la Renaissance.

Fifty years is a long run for a journal, but a short life for a university library. How do we teach Renaissance book history and culture at the University of Victoria, which celebrated its fiftieth anniversary in 2012-13?' Like other postwar Canadian academic institutions, we have had to buy all of our rare books long after they became rare, so we have only a small number of early print materials. We believe strongly that students need and want to hold the "real

1. A complete history of the University of Victoria is given in Ian MacPherson, Reaching Outward and Upward: The University of Victoria, 1963-2013 (Montreal: McGill-Queen's University Press, 2012).

Renaissance and Reformation / Renaissance et Réforme 37.4, Fall / automne 2014 
thing,"2 and that by doing so they learn both the strangeness of the past and its oddly familiar struggle with technological innovation. ${ }^{3}$ But what can they learn about the Renaissance from such a collection?

Although our archive is idiosyncratic, we claim that even a limited and not-very-representative collection of early printed books can be mobilized to teach concepts like intellectual history, material culture, interdisciplinary research, and periodization. We have developed a curatorial teaching model that invites students to find, select, and chart a narrative through the materials that we do have or can borrow. In doing so, we have discovered that the very partiality of our collection leads to wonderful opportunities for students to learn not just book history but also the history of universities, libraries, collectors, and Renaissance studies in Canada. In this essay, we will do three things: (1) outline the methodological justification for working with rare materials of any kind, (2) discuss practical steps to building an exhibit with student curators, and (3) document some of the projects we have undertaken with student curators.

\section{Foundational theory}

We regularly teach and research with open-access digitization and editing projects. We have library subscriptions to tools like Early English Books Online (EEBO) and Early European Books (EBO). We are well supported by open-access resources like The English Broadside Ballads Archive (EBBA), The Holinshed Project, and The Acts and Monuments Online (TAMO), and we look forward to the new Poly-Olbion Project and The Map of Early Modern London's (MoEML's) forthcoming edition of John Stow's Survey of London. So why do we need to march our students over to the Special Collections section of the campus library to look at rare books? We agree with scholars of book history

\footnotetext{
2. Eleanor Mitchell, Peggy Seiden, and Suzy Taraba talk about students' appetite for "the real thing," often whetted by digital surrogates. We would like to acknowledge as a whole their essay collection, Past or Portal? Enhancing Undergraduate Learning through Special Collections and Archives (Chicago: Association of College \& Research Libraries, 2012). This collection was published after we began our experiment in curatorial learning; the forty-seven essays and case studies therein offer a range of justifications and best practices to "teach undergraduates using resources in special collections and archives" (ix).

3. Here, we refer to the general assumption by many book historians that the book is a technology; see, for example, David C. Mengel, “Teaching the Codex as Writing Technology," Studies in Medieval and Renaissance Teaching 19.1 (2012): 25-38.
} 
generally, and with early modern book historians particularly, that digital surrogates, while valuable, cannot offer the same information that one derives from encounters with the object. ${ }^{4}$ A student will find it difficult to appreciate fully the technology of a book without turning its pages, much less to see each individual copy as a valuable witness to a complicated history of production, ownership, and influence.

Working with an early modern book teaches students not just that a text must be embodied to survive, ${ }^{5}$ but also that the text may be shaped by the ways in which it was initially embodied in its historical moment. ${ }^{6}$ For students of the Renaissance, understanding a print edition requires thinking about the production and price of paper, the implications of book size and format, and the typical workflow in a printing house, including the mechanics of composition and presswork. Handling a surviving copy from that edition teaches students that each copy of a handpress book is unique at press time. Online surrogates like $E E B O$ are misleading because they give the illusion of direct access to the early modern but inadvertently canonize particular copies. This problem is exacerbated by the decision of the Early English Books microfilm team, whose images $E E B O$ digitized, to omit blank pages and to photograph the cleanest available copy of a book. Blank leaves, stains, manuscript marginalia, and a custom-made binding alert us to the uniqueness of a copy and its reading history; picking an unannotated copy and failing to image its binding suggests that the text is somehow independent of the object and its readers. ${ }^{7}$ To get the

4. For foundational arguments about the importance of considering physical manifestations of texts, see Jerome McGann, The Textual Condition (Princeton: Princeton University Press, 1991). For important instances of early modernists pointing out the value of attending to actual copies of books, see Adrian Johns, The Nature of the Book: Print and Knowledge Making (Chicago: University of Chicago Press, 1998) and William Sherman, Used Books: Marking Readers in Renaissance England (Philadelphia: University of Pennsylvania Press, 2009).

5. By "embodiment," we mean oral delivery, manuscripts, and printed books as well as bytes and pixels.

6. A classic statement of this argument is Random Cloud's [Randall McLeod's] analysis of George Herbert's "Easter Wings" in "Fiat Flux," in Crisis in Editing: Texts of the English Renaissance, ed. Randall McLeod (New York: AMS, 1994), 61-172.

7. Diana Kichuk gives a history of $E E B O$ and a balanced critique in "Metamorphosis: Remediation in Early English Books Online (EEBO)," Literary and Linguistic Computing 22.3 (2007): 291-303. She notes that "There is a measurable loss of qualities unique to the original medium and a simultaneous gain of qualities unique to digital media" (300). Early European Books, because it captures bindings, edges, and blank pages in high-resolution colour scans, is a better digital tool for teaching materiality. See also 
richest possible understanding of a printed text, therefore, students need to experience that text in its native medium.

Such understanding helpfully disrupts some of the assumptions built into university curricula. Renaissance courses in English departments, for example, imply that literary texts were central to this culture, that England was an international superpower, and that this period was more technologically sophisticated than the Middle Ages and less so than our own cultural moment. A survey of all the matter printed in a year (most of it non-literary), comparison of English and Continental books (the latter more elegant), and appreciation of the skill required to produce any particular volume challenge those implications. Even more importantly, engagement with early books knocks down period boundaries. The lens of periodization that structures undergraduate course offerings is a constructed practice of reading and a set of arguments and assumptions about relevance. As the editors of a Journal of Medieval and Early Modern Studies special issue on periodization put it, "Assigning literary texts to a specific period tethers them to the moment of their composition: yet the nature of literary texts and stories is to circulate, allowing consumption to take place at a great remove from composition." 8 The long shadow of the Renaissance can be traced by the books that have survived and come into our hands.

Every volume records a history of its own survival that constitutes, in effect, a story of how the Renaissance has shaped subsequent generations and how it has been understood by them. A lavish nineteenth-century binding on a cheap sixteenth-century book tells us something about its post-Renaissance reception. One of UVic's two copies of the 1599 Geneva Bible, identified in our catalogue as the "Historic Scarnell Family Breeches Bible," contains a handwritten genealogical inscription relating to the Scarnell family (1740-1860), suggesting that a 250 -year-old book could be seen not as museum piece but as a functional family Bible and record repository. ${ }^{9}$ We also have in our collection a number of volumes that appear to have passed through the hands of linguist and theologian William Wotton (1666-1727). His copy of Calvin's Harmonie

Ian Gadd, “The Use and Misuse of Early English Books Online," Literature Compass 6.3 (2009): 680-92; and Bonnie Mak, "Archaeology of a Digitization," Journal of the Association for Information Science and Technology 65.8 (2014): 1515-26.

8. Jennifer Summit and David Wallace, "Rethinking Periodization," Journal of Medieval and Early Modern Studies 37.3 (2007): 448.

9. [The Geneva Bible] (London: C. Barker, 1599). 
on the Three Evangelistes (1610 edition of the 1584 English translation) is heavily annotated, revealing that Reformation issues were still very much of interest to eighteenth-century thinkers. Studying the history of particular copies leads students inductively to key questions for our field: what's the link between the Renaissance and the development of print culture, and how does the rise of print affect the spread of the Reformation?

Holding an early printed book invites us to rethink what we mean by knowledge. When we replicate printed texts in a different medium, whether a modern edition or an online surrogate, we privilege the content and gain portability, affordability, scholarly apparatus, and legibility for a modern reader. But we lose all the haptic data, including the sensory dimensions of reading: the weight of the book, the texture of the pages, the smell and colour of the binding, and the space the book occupies. That data can tell us about the reception history of the book. Marginal notes, pen-testing, doodles, and damage hint at how later readers valued a book and its contents; pressed flowers, family trees, and documents stored in books tell us that these volumes were not just vehicles for the conveyance of text. In addition, the experience of the material object inspires students to see themselves as part of a historical continuum. As G. Thomas Tanselle writes,

the wonder is not only that these things have an independent existence but also that they seem to have had a pre-existence-that is, to have a history that antedates our awareness of them. The act of reaching out and touching them therefore produces contact both with the environment and with the past. ${ }^{10}$

While wonder alone is not sufficient justification for handling rare materials, ${ }^{11}$ we can mobilize that wonder to raise questions both about the object and about its history before and after the current reader. 


\section{The problem-and some solutions}

Given the value of having students work with real examples of early modern books, how do we achieve that ideal at a young university with a relatively small and quirky rare book collection? When the University of Victoria opened in July 1963, the year before Renaissance and Reformation began publication, its library ingested the Victoria College Lansdowne campus collection, including a small number of rare books. The University Senate imagined that Special Collections, established in 1966, would “act as a 'research laboratory' for honours and graduate programs especially in the fields of English Literature, History, and History in Art." ${ }^{\prime 2}$ Although UVic was charged with a special responsibility to collect "English and Anglo-Irish Literatures, military history and UVic authors while U.B.C. collected B.C. authors and Simon Fraser, American Literature," UVic has specialized not in Renaissance and Reformation English literature, but in high Modernism, and, more recently, "Canadian Literature with a particular emphasis on Vancouver Island and Victoria writers and publishers." ${ }^{13}$ Even when funding was plentiful, UVic directed its resources to periods later than those covered by this journal.

What we do have in this area, therefore, arrived mainly via private donations, faculty bequests, and targeted purchasing for specific research needs. We have 4,500 English books from the handpress period. ${ }^{14}$ However, only six are from the sixteenth century, and three of those date from the 1590s. We have 385 seventeenth-century books, 261 of which are post-Restoration (1660-99). Highlights include a first edition of John Donne's Pseudo-Martyr (1610); a beautiful red-ruled copy of the 1610, two-volume edition of John Foxe's Acts and Monuments; a second issue of the first edition of Michael Drayton's PolyOlbion (1613); Fynes Moryson's Itinerary (1617); and Thomas Heywood's 1624 Gynaikeion, or, Nine Bookes of Various History Concerninge Women (the last of which was acquired in 2014 at Jenstad's request). We have more than a dozen sixteenth-century and over a hundred seventeenth-century French books

12. “General Development of Special Collections," accessed 8 March 2014, http://www.uvic.ca/library/ locations/spcoll/about/collection.php.

13. "English Literary Collections," accessed 8 March 2014, http://www.uvic.ca/library/locations/spcoll/ about/collection.php.

14. There is a sortable list of these books at http://titan.library.uvic.ca/earlybooks/recordlist.php (accessed 8 March 2014). 
(mainly in the Seghers Collection, on permanent loan ${ }^{15}$ ), and thirty-five sixteenth-century and twenty-one seventeenth-century Italian books. Highlights among our Continental books include three Aldine octavos, the emblem book Livret des emblemes de Maistre Andre Alciat (1536), and Vesalius's anatomy De humani corporis fabrica (1555).

English students can learn about the book as a technology from French, Latin, and German early books in our collection, but the alienating effect of the language exacerbates the alienation effect of the material book in its early form. We have found that effective undergraduate pedagogy combines the known and the unknown. Working with our 1610 Pseudo-Martyr capitalizes on students' acquaintance with John Donne, whose poetry many English majors have read in an anthology, and makes them more curious about the unfamiliar material form of the quarto.

In our regular teaching, we confront the gaps in our collection on a weekly basis. We teach a class entitled Introduction to Textual Studies and Methods of Research, a required course for all incoming English graduate students that meets weekly in the classroom adjacent to the Special Collections Reading Room. As instructors, we try to identify at least one item in the collection that speaks directly to the stated research interests of each member of the course, an easy goal to meet for our students of West Coast Literatures but more challenging for us when a student declares an interest in sixteenth-century drama. Many authors, publishers, countries, and sometimes whole decades are not represented in our collection. When we take a Shakespeare or British Literature class to Special Collections, we cannot show them a Shakespeare folio. We settle for "something from the period," or perhaps a neoclassical edition of a text so that they can see how the medieval and early modern periods piqued the interest of later generations.

Our most rewarding and effective teaching in the last few years has been accomplished in conjunction with exhibitions. We cannot mount an exhibition comprised entirely of Renaissance books - or rather, we could, but it would be small and thematically disjointed. Making a virtue of necessity, we have discovered that having fewer materials encourages in students the curiosity, lateral

15. See the description of the Seghers Collection at http://www.uvic.ca/library/locations/spcoll/book/ seghers.php (accessed 8 March 2014), and also Hélène Cazes, The Seghers Collection: Old Books for a New World (Victoria, BC: University of Victoria Libraries, 2013), online at https://dspace.library.uvic. ca:8443//handle/1828/4742 (posted 2013). 
thinking, and interdisciplinarity that is crucial to their training in Renaissance studies. The value of a curatorial approach is that one curates what one has. We do not normally have the resources to borrow objects that represent a predetermined theme, so the challenge resides in connecting the objects that reside here in Victoria.

This challenge models for students the processes of scholarship. As humanities scholars, we rarely begin with a thesis or even a hypothesis; instead, we notice patterns and follow our curiosity. Our students, however, often develop premature theses. Having them confront an unfamiliar object demands that they pose questions before offering answers. ${ }^{16}$ An incomplete collection naturally presents puzzles. When a library's acquisition policy is not to "make sure we have something representative of every author, period, movement, and genre," then one has to ask why a collection includes anything outside its acquisition remit. The question "How did this book end up here?" leads to a host of related questions about provenance, canonization, legacy, collectors, collections, book dealers, conservators, and the circulation of material objects over time, through networks, and across continents. ${ }^{17}$ In sum, the curation of books invites students to construct and examine their own relationship to other times and places.

Between the two authors of this article, we have curated (separately or together) four exhibitions with student volunteers, all of whom were already comfortable writing traditional essays. An exhibition makes useful new demands; for them, curation is "an entirely new method of knowledge production and analysis." ${ }^{18}$ We work with the students to identify the theme of the exhibition. With help from library staff, we find all available materials relevant to that theme, expanding or contracting our scope as necessary as we discover either a

16. Carla Mary Rineer and Marilyn McKinley Parrish's "Engaging the Text" (Past or Portal, 113-18) describes an assignment that requires students to develop an essay based on a primary source item from their university archives. Rineer stresses that this process involves having students "engage with a primary source, ask questions, read some secondary material, and construct a thesis that more accurately reflects the facts" (113) rather than starting with a thesis or hypothesis and finding data to support their assumptions. Both authors note that this activity makes students "makers of meaning" and involves them directly in "the scholarly conversation" (118). This result is exactly what we found as well.

17. Tanselle, 1-25.

18. Laurel Bradley, Kristi Wermager, and Gabriel Perri Silberblatt, "Exhibiting Artists' Books: Three Perspectives from a Curatorial Seminar," in Past or Portal, 242-47; quotation from 242. 
paucity or plethora of objects. We carve out an exhibition narrative as we select materials that will honour the collection, intrigue visitors, and best support the emerging narrative or thesis. We write documentation in the form of exhibition guides, placards, and item display cards. We mount items in display cases, and host an opening event and tours. ${ }^{19}$ In all four of our exhibitions, our general topic responded to a library initiative or community event, which put us in the position of canvassing the collection for relevant items.

\section{Case studies}

Jenstad's first project, in spring 2012, was a donor-focused exhibition celebrating founding UVic English faculty member Patricia (Pat) Köster, whose collection of rare books was donated to Special Collections after her death in 1996. Köster was an eighteenth-century specialist, but her collection ranged from a 1526 Latin Vulgate Bible printed in Leiden to her personal reading copy of Ulysses. One purpose of the exhibition was to recognize the ongoing contributions of Karl Köster (Pat's husband) towards the conservation of these books. The goal was to produce both a conventional exhibition of more than one hundred volumes under glass, and an invitation-only event where guests (many of them potential donors) could pick up and examine an additional seventy-five volumes. The curatorial team was comprised of Jenstad and doctoral candidate Sandra Friesen (an expert in Restoration literature and holder of the Pat Köster Scholarship in Women's Writing, 1660-1900), assisted by graduate students Jillian Phillips and Kevin Elliot and undergraduate student Alexandra Coates. ${ }^{20}$

This exhibition presented the curators with several challenges. First was the huge amount of material; the Köster collection includes over four hundred

19. Our process, determined by trial and error, is in keeping with what Bradley, Wermager, and Silberblatt describe as the learning outcomes of their one-term curatorial seminar for (mostly) art history majors. The authors helpfully outline what students must do and learn in such a seminar, especially if they are going to end up with a successful exhibit: "students must quickly acquire at least a superficial mastery of a specific field before conceptual and practical work can begin; familiarize themselves with the college holdings within that field [...]; perfect the art of writing museum labels for public consumption; and navigate the complexities of a group project even while making high-quality individual contributions" (“Exhibiting Artists' Books," 242).

20. The exhibition was to have been curated by librarian Danielle Forster with Jenstad's assistance. Sadly, Forster passed away in September 2011. We would like to acknowledge her vision for the library's Special Collections as a venue for exhibitions. 
titles amounting to over one thousand volumes, plus Köster's research notes. To mount a donor-focused exhibition, we (Jenstad and Friesen) felt the need to look at every item she had donated. The library had a printed finding-list of short titles but no copy descriptions and no indication of why, how, or when Köster acquired each title. Second, the organizing principles of a collection like this one are the personal interests, history, and sometimes arbitrary finds of the collector. As Walter Benjamin asked of his own library, "what else is this collection but a disorder to which habit has accommodated itself to such an extent that it can appear as order?"21 We needed to work out-from the evidence of her books-what Köster's collecting habits were. Once we had done so, our final challenge was to take materials that we thought were intrinsically interesting and make that interest evident to the general public.

We spent Friday mornings for four months going through carts of all of Köster's books, looked for patterns in the collection, and sorted the books onto "yes," "no," and "maybe" carts. Our guiding questions were always "How do we showcase the collection in a way that reveals something of the life and mind of the collector?" and "How can we use this exhibition to further Köster's legacy as the long-time instructor of the bibliography course?" Some groupings reflected Köster's research interests as a scholar of the long eighteenth century and of women's writing. We chose representative examples and grouped them under the headings "Conduct Books," "Women Writers," "Eighteenth-Century Writers (1660-1800)," "Biographies, Memoirs, and Letters," "Religious Writing," "Bibles," "Classical Texts," and "Talk of the Town: Satire, Characters, Gossip." Other groupings spoke to Köster's interests as a bibliographer; we had tables of materials representing "Paratexts," "Writing in Books," and "Book Conservation."

Working with the student assistants, we wrote a rich description for each category, then a bibliographical description and an accompanying contextual note for each title. These materials were written to be clear and compelling to a general audience. For example, Köster owned a copy of Bell's edition of The Poetical Works of Will. Congreve. ${ }^{22}$ Our exhibition card explained the volume's importance:

21. Walter Benjamin, "Unpacking My Library: A Talk about Book Collecting," in Illuminations: Essays and Reflections, ed. Hannah Arendt and trans. Harry Zohn (New York: Schocken, 1969), 60. Partially quoted in Tanselle, 7 .

22. William Congreve, The Poetical Works of Will. Congreve (Edinburg [sic]: At the Apollo Press, by the Martins, 1778). This was vol. 36 of The Poets of Great Britain from Chaucer to Churchill. 
Bell's Editions of the poets, a collection of canonical poets' biographies and central works of which Pat collected over a dozen separate volumes, was the inspiration for Samuel Johnson's Lives of the English Poets (1779-81). Most scholars have pronounced the volumes of Bell's Editions trifling and insignificant without even looking at them. Pat was one of the first twentieth-century scholars to give Bell's Editions serious attention. It's therefore fitting that she should have collected these volumes.

This duodecimo volume is not flashy, but it bears witness to eighteenth-century processes of canon formation. Our copy thereof bears witness as well to scholarly recovery of an overlooked facet of cultural history.

While building this exhibition, the students acquired a number of skills. They learned how to extract information from the title page or colophon of an early printed book. They used a variety of research tools, including the English Short Title Catalogue, the Stationers' Register, Eighteenth-Century Collections Online, and the Oxford Dictionary of National Biography. As forensic bibliographers, they learned how to handle rare books. As curators, they learned to display fragile materials safely, using Mylar film to hold books open and foam book supports to protect the spines. As docents for the "white glove event," as we called it, they shared their knowledge with our visitors. They learned techniques for determining the provenance of a volume. They discovered something about the history of the university and its people, and about how collections develop, since we had access to Köster's CV, her early publications, and her research notes. And, of course, they learned about Renaissance and Reformation titles that were printed over the span of four centuries (from a 1528 Bible to a 1904 edition of Rabelais).

Individual students involved in this project had research triumphs. MA candidate Jillian Phillips first encountered Reverend John Wilkins's Mercury: Or the Secret and Swift Messenger (2nd edition; 1694) in the Introduction to Textual Studies course taught by Kelly. While working on the exhibition, she met this quarto again in the context of the Köster collection and wrote the exhibition display explaining that "The book contains various codes, ranging from symbols to letters, that would allow a letter-writer to encode a letter to prevent discovery of the content by anyone other than the intended recipient." Phillips subsequently undertook an independent study, under the direction of Kelly, on 
Wilkins's understanding of language. Having completed her MA in English, Phillips is now pursuing an MLS degree at Iowa State University. ${ }^{23}$

Together Friesen and Phillips discovered that Köster's worn but beautiful first edition of Dryden's The Works of Virgil (1697) was likely part of a scheme to raise funds for the massive translation project by making deluxe copies available to those who paid for subscriptions before the book was printed. Their display card explained that it

was very possibly one of many that were printed specifically for the project's advance subscribers. In return for their advance payment of five guineas, each subscriber was honoured with a dedication under one of the volume's many full-page plates, and was given a copy of the volume printed on larger and better quality paper (as this copy is).

By working with this volume, the students learned that big books were expensive and required patronage from individuals and institutions even to come into being; they also came to recognize that the printed books we are used to thinking of as mass-produced objects might be customized for individual owners.

Our next two exhibits came about as a result of a fortuitous combination of past and present university and community interests. In 2011, the library initiated a partnership with Pacific Opera Victoria (POV). ${ }^{24}$ POV artistic director Timothy Vernon has made a special study of operatic adaptations of Shakespeare's plays, regularly including such adaptations in the POV season. Fall 2012 and fall 2013 respectively saw productions of Verdi's Macbeth and Falstaff. Having committed to the library-POV partnership, we needed to mount exhibitions that would teach the general public about connections between Shakespeare and opera. The Macbeth and Music exhibition (4 October to mid-November 2012) was curated by Jenstad with assistance from students Sarah Dawson, Telka Duxbury, Noam Kaufman, Nathan Phillips, and Brittany

23. See Phillips's library blog post about her continued work on Wilkins at http://uispeccoll.tumblr.com/ post/74394281820/rev-john-wilkins-1614-1672-was-an-incredibly (posted 24 January 2014).

24. The University of Victoria Libraries curated an exhibition called The World of Mary's Wedding: Reminiscences of World War I from UVic Archives and Special Collections to coincide with Pacific Opera Victoria's 2011 premiere of the new Canadian opera Mary's Wedding. The companion online exhibition is available at http://worldofmaryswedding.library.uvic.ca/ (accessed 8 March 2014). 
V. Vis. Falstaff and Music (16 September to 29 November 2013) was co-curated by Jenstad, Kelly, Duxbury, and Phillips, with research assistance from Cameron Butt and curatorial assistance from Alina Blank and Alexandra Coates. ${ }^{25}$

As Jenstad and Friesen had done with the Köster exhibition, for both of these Shakespeare exhibitions we assembled a team, selected materials, and described and contextualized the materials for display. The main challenge in this case was that our collection has only one copy of the first English edition of Verdi's Falstaff, no early editions at all of Verdi's Macbeth, and, of course, no editions of Shakespeare's plays printed before the 1720s. But we did have many items that represented the long afterlife of Shakespeare and Verdi, such as eighteenth- and nineteenth-century illustrated editions of Shakespeare, performance ephemera (from the Internet Shakespeare Editions [ISE], from theatre archives deposited in Special Collections, ${ }^{26}$ from local collectors, and from colleagues), editions and recordings of Verdi from the Music Library, and musical scores for songs from, and inspired by, Shakespeare's plays (mainly from the Shakespeare Music Project fonds). ${ }^{27}$ These materials presented us with a challenge, however. As researchers, we have been trained primarily to work with early modern books, yet we found ourselves handling theatre programs, nineteenth-century pianoforte sheet music, a unique music manuscript, prompt books, Ian McKellen's gloves, ${ }^{28}$ and numerous other artifacts we had to teach ourselves to understand as well as present.

25. In both cases, we were grateful for help from the staff in Special Collections: Lara Wilson (head of Special Collections and university archivist), Jane Morrison (associate archivist), and library assistants Nadica Lora and John Frederick.

26. Theatrical ephemera were deposited with Special Collections by local companies (the New Bastion Theatre Company) and by retired faculty members John Krich and Harvey Miller. They are described, respectively, at http://www.memorybc.ca/new-bastion-theatre-company-fonds (accessed 8 March 2014) and at http://www.memorybc.ca/john-krich-and-harvey-miller-theatre-collection (accessed 8 March 2014).

27. We were able to mount a rich exhibit of related materials because of the library's extensive holdings in Shakespeare and music, thanks to the 1980s SSHRC-funded Shakespeare Music Project. After publishing A Shakespeare Music Catalogue, ed. Bryan N. S. Gooch and David Thatcher, 5 vols. (Oxford: Clarendon Press, 1991), the lead researchers deposited the project's research materials in the UVic Special Collections. See the description of Fonds AR116 at Memory BC: The British Columbia Archival Information Network, accessed 8 March 2014, http://www.memorybc.ca/shakespeare-music-project-fonds;rad.

28. The black leather gloves worn by Ian McKellen in the Royal Shakespeare Company's 1979 production of Macbeth (dir. Trevor Nunn, starring Judi Dench as Lady Macbeth to McKellen's Macbeth) arrived 
We developed a model for the Macbeth and Music exhibition that we were able to adapt for Falstaff and Music and could extend to future projects. Given the nature of the materials and our respective areas of expertise, we took a "divide and conquer" approach. We matched individual students with sets of artifacts that complemented their interests and previous research experience. Artifacts divided into logical groups: Shakespeare Texts and Editions, Sources and Adaptations, Musical Scores, and Theatrical Ephemera. MA student Sarah Dawson had trained as an opera singer, so she worked on Verdi. As research assistant for the ISE, Telka Duxbury had digitized and created metadata for performance artifacts, so it made sense for her to select and describe theatrical ephemera from the ISE collections, the Krich-Miller fonds, and the Shakespeare Music Project fonds. Since we knew by December 2012 that we would be mounting Falstaff and Music in fall 2013, we were able to have undergraduate student Cameron Butt, who wrote his honours thesis on Falstaff, develop a finding aid that listed and described all our Shakespeare holdings.

The most important lesson for the students came from the need to chart a narrative through disparate materials from various disciplines across a wide span of time. Again, we found ourselves asking questions of the materials before formulating a thesis. With Macbeth, the preponderance of settings for the witches' songs, combined with the recurring illustrations of the witches dancing (both in editions and theatrical ephemera), pointed us back to the early text. The only surviving early text of Macbeth is the 1623 folio version, which we know to have been revised by Thomas Middleton whose main contribution was the songs for the witches. That Macbeth has always been a musical adaptation became the theme of our exhibit. In other words, the adaptive tradition we were tracing was very much a Renaissance phenomenon.

Gathering materials for Falstaff and Music was more complex because Falstaff appears in various guises and with different names in Shakespeare's 1 Henry IV, 2 Henry IV, Henry V, and The Merry Wives of Windsor; the anonymous plays Famous Victories of Henry the Fifth and Sir John Oldcastle; historical accounts in Foxe's Acts and Monuments and Holinshed's Chronicles; and various adaptations, including operas and novels. Our exhibition traced Falstaff's history on page and stage, from his early life as Sir John Oldcastle all the way to the 2013 one-man show Falstaff written and presented onstage by local

in Victoria as a donation from the RSC to the now-defunct Bastion Theatre. 
playwright-performer Clayton Jevne. The theme of this exhibition became Falstaff's enduring Renaissance characteristics. We noticed how subsequent productions reconstructed Renaissance ideals; because The Merry Wives of Windsor has almost always been set in Tudor costume and celebrated as quintessentially Shakespearean, productions and adaptations give us access to what the Renaissance has meant to subsequent generations. Overall, the students learned that our understanding of the Renaissance is always shaped by later manifestations, adaptations, scholarship, and cultural appropriations.

At the same time as Falstaff and Music, we mounted an exhibition entitled Shakespeare's Big Books which featured the four seventeenth-century folio editions of Shakespeare's plays. ${ }^{29}$ The second and fourth folios (published in 1632 and 1685 respectively) came from the Legislative Library of British Columbia. We borrowed a first folio (1623) and an exceedingly rare third folio (1663) from the University of Toronto Thomas Fisher Rare Book Library. This exhibition marked the first time that F1 and F3 had travelled outside Toronto and the public debut of the Legislative Library folios. The exhibition contextualized the printing of Shakespeare's works in relation to book history, manufacture, and collecting. We selected sixteenth- and seventeenth-century books from UVic Special Collections to showcase different book sizes from the thumb-sized $64 \mathrm{mo}$ to the back-breaking imperial folio, and explained other features of book history with text and images presented on wall panels. This exhibition was held in a downtown gallery space owned by the university. Over the course of nineteen days, nearly 1,400 people visited the exhibition, from the lieutenant governor of the province to tourists coming in off the street. Media coverage included a front-page story in our local newspaper, interviews with $\mathrm{CBC}$ and $\mathrm{CTV}$, and articles in numerous campus and community publications.

This exhibition differed from the others we mounted not just in terms of the number of visitors and amount of high-profile attention, but also in that we curated it with limited student help. The contrast helped us recognize the value of teaching book history and Renaissance studies through curation. Because of the value and rarity of the Shakespeare folios, as well as the contractual obligations built into the loan contracts, we could involve students only in preliminary

29. This exhibition was part of a larger community-university collaboration called Shakespeare OnstageOffstage. We are grateful to the University of Victoria Libraries (particularly to university librarian Jonathan Bengtson and associate university librarian Wendie McHenry) and the Legacy Gallery for their major role in funding and hosting the exhibition. 
research and groundwork, not in the selection and description of materials or the mounting of the exhibition. We mobilized a team of students as docents once the volumes were in their high-security cases, but these students could not handle the books, turn the pages, or engage with the individual copies. We taught them enough about the history of Shakespeare in print and the provenance of these volumes in particular, and book history generally, to be able to answer questions from gallery visitors. But we were deeply conscious that we were conveying information rather than having the students learn experientially. The restrictions on this exhibition confirmed for us that the limitations of our collection can be a benefit. Because most of UVic's rare books are not exceptionally precious, we invite students to touch them, to help us curate exhibitions around them, and to learn from them as material artifacts. Furthermore, the folios exhibition raised questions for us and our students about why some books are valued more than others. Some UVic Special Collections volumes are actually rarer than the Shakespeare first folio. The English Short Title Catalogue lists only thirty-one copies of our new acquisition Heywood's Gynaikeion (1624); Shakespeare's first folio, printed only a year before, survives in more than 230 copies. We learned that the idea of the Renaissance has been constructed partly by market forces and reading consumers.

The amount of community interest convinced us that we need to find ways to create virtual exhibits that invite the general public and larger audiences to engage with materials in our Special Collections. Libraries hold material that is not visible to the scholarly world or to students. Our students have become part of the ongoing process of surfacing our hidden collections in BC. We have already mentioned that Butt created a finding aid for Shakespeare materials in our Special Collections. He was able to do so mainly by searching our catalogues for the keyword "Shakespeare." However, some of our collections are more difficult to identify and access. While researching their hitherto unknown Shakespeare folios, we learned that the Legislative Library contains an uncatalogued rare book collection, including several sixteenth- and seventeenth-century bibles. The mysteries of this collection provided a unique opportunity for a research student to obtain funding through the University of Victoria's Jamie Cassels Undergraduate Research Award (JCURA) program. ${ }^{30}$ Undergraduate

30. See the description of the JCURA program at http://www.ltc.uvic.ca/scholarships/jcura.php (last modified 25 June 2014). This highly successful program has few analogues, but see the description of 
English honours student Kaelan Unrau created a finding aid that lists all the bibles and exegetical early printed books in Victoria libraries, including those at UVic Special Collections and the Legislative Library.

To create this finding aid, Unrau had to determine what exactly is important information about each book both as an example of that edition and as a unique object (descriptive bibliography and analytic bibliography). His catalogue entries confirm the identity of the item (using ESTC and EEBO), then offer bibliographic description of the ideal item as well as notes about the unique features of the copy, including descriptions of bindings, manuscript annotation (which necessitated palaeographical study), and any ownership or provenance marks or records. Unrau used the $O D N B$, genealogical records, Google Scholar, and other sources to track down information about previous owners. This finding aid will be available in print and online through the UVic Special Collections. Just as an exhibition is not merely a group of objects but a narrative, a finding aid is not merely a list but a scholarly argument about what matters. This kind of work invites the student to think about which materials belong together, and what we need to know about them. It also opens up fundamental questions of definition. ${ }^{31}$ What do we mean by a Renaissance book? What counts as an exegetical text? Is a sermon a biblical commentary? Is a Book of Psalms bound with the New Testament a Bible?

Another recognition from our exhibitions was the need for a finding aid for the Shakespeare Music Project fonds, which consists of twenty-nine metres of textual records. ${ }^{32}$ The existing finding aid, an unpublished Word file, lists sub-groups in the fonds but does not indicate the presence of hundreds of photographs of original sources, original printed scores, and performance ephemera including programs and posters. We are particularly keen to catalogue the printed scores in such a way that they can be found by literary

the Excel program in Diane Windham Shaw, "Waiting to Excel: Undergraduate Research Partnerships in Special Collections at Lafayette College," in Past or Portal, 261-65.

31. Such arguments are what Jeanne Fahnestock and Marie Secor identify as second-stasis arguments of definition and see as foundational to literary critical debates; "The Rhetoric of Literary Criticism," in Textual Dynamics of the Professions: Historical and Contemporary Studies of Writing in Professional Communities, ed. Charles Bazerman and James Paradis (Madison: University of Wisconsin Press, 1991), 76-96.

32. Fonds AR116 in the MemoryBC archival network. See http://www.memorybc.ca/ shakespeare-music-project-fonds (accessed 8 March 2014). 
scholars; at the moment, we index items in this collection by composer but not by Shakespearean source. Duxbury, who worked with us on the Macbeth and Falstaff exhibitions, undertook as a graduate directed reading project the task of creating the prototype for a "Shakespeare and Music" database. She determined what kind of information we should record about each artifact in the searchable fields known as metadata. The process of creating the finding aid required her to determine which features to describe, how to describe them, and what taxonomies and standardized language to use in her descriptions. ${ }^{33}$ Like Unrau, she had to determine provenance, confirm publication details, and contextualize the named persons by using standard research tools and calling upon the human resources in our library and the larger community. Her perspective as a literary scholar has enabled her to link these Baroque, Classical, and Romantic adaptations back to their Renaissance sources.

Our curatorial work, for both physical and virtual exhibitions, is necessarily interdisciplinary, collaborative, and community-directed. We genuinely need the expertise and energy of our student assistant curators to complete and enrich these complex projects. We rely upon the good will of library professionals and community donors to support our exhibitions, and we feel an obligation to share our knowledge and resources with the community at large. Finally, we plan ahead for digital preservation of both the materials and the exhibition narratives. The connections we have drawn between available materials point towards new projects and, more generally, towards new possibilities for Renaissance studies. Introducing classes to these materials not only helps us identify which students are most interested in becoming involved in curatorial projects but also what subjects might be explored in future exhibitions. Student questions about how digital humanities projects represent early printed books and how paratextual elements like indices, marginalia, and title pages constitute information technologies will likely shape future exhibitions. As well, an obvious next step is to teach a course structured around an exhibition. ${ }^{34}$

\footnotetext{
33. Duxbury's process was similar to the process undertaken by the "student researcher/catalogers" described by Rachel Sagner Buurma, Anna Tione Levine, and Richard Li in "The Early Novels Database and Undergraduate Research: A Case Study," in Past or Portal, 279-82. Here, the students "have been involved in the process of creating a bibliographic template of information we want to capture" (281).

34. This model is described by Marianne Hansen, "Real Objects, Real Spaces, Real Expertise: An Undergraduate Seminar Curates an Exhibition on the Medieval Book of Hours," in Past or Portal, 237-41; and Bradley, Wermager, and Silberblatt, "Exhibiting Artists' Books."
} 


\section{The past in the present}

As scholars of Renaissance and Reformation studies, we are well aware of the constructed and occasionally arbitrary nature of disciplinary boundaries and period parameters. We regularly question what we mean by a term like "Renaissance," and can spend hours debating whether "early modern" is a more useful label and whether Milton's Paradise Lost belongs to the Renaissance or the long eighteenth century. (Such debates are a regular feature of curriculum committee meetings.) Our students, however, come to these studies via course titles, anthologies, and major program requirements that convey a hermetic solidity upon the notion of "Renaissance." Our own institutional structures cordon off knowledge into tidy units that are not in fact shared by the broader community in which we live and in which books have been preserved. Our students come to us from an environment where Shakespeare is very much alive on stage, at the cinema, and in popular culture. Many undergraduates come to university having been unknowingly steeped in Reformation texts and debates while attending church services or engaging in conversations about religion in their family homes. Our first curatorial ventures were triggered by community partnerships because people in greater Victoria think the Renaissance is relevant to their lives.

Taking the curatorial approach we have described certainly introduces book history, but, more importantly, it usefully troubles the notion that period and disciplinary boundaries are fixed. As Renaissance and Reformation specialists, we might, in a larger library, have curated exhibitions comprised entirely of books from the incunabular period to the late seventeenth century. Because we work with a young, western Canadian library, we were forced to think outside our normal period boundaries, and even outside our disciplinary boundaries. We had to situate our small collection of early printed books alongside musical scores, theatrical ephemera, images, maps, films, and later books. Doing so made us and our students recognize the extent to which we are still living with the legacy of the Renaissance. This period still shapes us, and, what is more, our understanding of it is always filtered through the lens of intervening generations. Their curatorial work taught students that the past survives through objects and through remakings. Holding a sixteenth-century book that had seventeenth-, eighteenth-, nineteenth-, and twentieth-century owners before it came into our hands makes explicit that the past lives in the 
present. Looking at an eighteenth-century edition, a nineteenth-century Verdi score, or a recent Stratford Festival theatre program shows clearly how we keep remaking the Renaissance, inevitably in our own image. Having fewer materials at our disposal invites our students to think about legacy in multiple ways: how works survive, how they are collected and transmitted, the transformations they undergo across time and through media.

This process forces undergraduate students to confront the big questions that usually come later in graduate training for scholars of the Renaissance. What was or is the Renaissance? When did it begin and end? What is or was the Reformation? How do English and Continental traditions differ and converge? Which items make the cut when it comes to canon-formation? As well, it raises questions of general humanistic importance. How do we know what matters when we look at objects from the past? When is the past? What is its relevance to the present? In order to teach Renaissance studies effectively, we need to encourage students to engage with such issues; not surprisingly, these are the very issues that have always been of interest to the scholars who read and publish in Renaissance and Reformation/Renaissance et Réforme. We encourage other scholars across Canada to engage in curatorial approaches that invite students into the conversation ongoing in these pages. 